\title{
GESTÃO AMBIENTAL NA FORMAÇÃO DA IMAGEM CORPORATIVA: O CASO DAS AGÊNCIAS DO BANCO REAL EM CONSELHEIRO LAFAIETE/MG
}

\author{
ENVIRONMENTAL MANAGEMENT IN THE ORGANIZATIONAL IMAGE FORMATION: THE CASE OF \\ AGENCIES OF THE BANCO REAL IN CONSELHEIRO LAFAIETE/MG
}

\author{
Renata Giacomin Menezes \\ Universidade Presidente Antônio Carlos - UNIPAC/MG
}

\section{Reinaldo Dias}

Centro Universitário UNA/MG; Universidade Presbiteriana Mackenzie/SP

\section{RESUMO}

A crescente preocupação da sociedade com as questões ambientais tem levado as empresas a se preocuparem, cada vez mais, com o controle dos impactos ambientais através da implantação do Sistema de Gestão Ambiental. 0 presente trabalho busca analisar a gestão ambiental como ferramenta estratégica competitiva na formação da imagem corporativa e reforçar a importância das organizações adotarem práticas de preservação ambiental para melhor atender a empresa e a sociedade em que está inserida. 0 trabalho trata-se de um estudo de caso com a utilização da pesquisa de caráter exploratório com descrições qualitativas e quantitativas, pesquisa bibliográfica e documental, além do trabalho de campo composto de entrevistas estruturadas em questionários semi-fechados, com objetivo de analisar o comportamento do consumidor diante da imagem ambiental corporativa.

Palavras-chave: Meio ambiente. Gestão ambiental. Empresas. Imagem corporativa.

\begin{abstract}
The great concern of the society with environmental issues has made companies worried about the environment impact control through the Environmental Management System implantation. The present research has as its objective to analyze the environmental management as a competitive strategy tool in the formation of the organizational image and state the importance of the organizations to adopt environmental preservation practices to assist better the company and the society already insert. This research talks about a case study with the use of exploratory data research with quality and quantity descriptions, bibliographic and documental research, besides field research based on structured interviews in semi closed questionary, with the objective of analyzing the consumer behavior before corporative environmental image.
\end{abstract}

Keywords: Environment. Environmental management. Companies and corporative image. 


\section{INTRODUÇÃO}

A expressão meio ambiente tem sido mundialmente difundida pelos diversos meios decomunicação, mostrando a preocupação da sociedade com a degradação ambiental, decorrente da poluição do ar, das águas, do solo e do desmatamento excessivo e desnecessário (DREW ${ }^{1}$ apud SANTOS, 2006).

Historicamente, o meio ambiente sofreu um processo de aceleração de sua degradação proporcionalmente à velocidade do desenvolvimento do capitalismo, privilegiando o lucro e colocando a questão ambiental em segundo plano (LAYRARGUES, 2000).

Conforme Capra (1996) à medida que os conceitos, objetos e a imagem que temos de nós mesmos começaram a ficar cada vez mais complexo e variado, o ser humano começou a perder o contato com a natureza e a se transformar em indivíduos cada vez mais fragmentados. Por isso existe a relação entre a expansão rápida da população com a escassez 4cada vez maior dos recursos naturais e a degradação contínua do meio ambiente.

Segundo Donaire (1999), para muitas organizações a variável ambiental, do ponto de vista empresarial, está diretamente relacionada com o aspecto econômico. Mas, felizmente algumas organizações têm demonstrado que é possível ter rentabilidade sem deixar de contribuir para a minimização dos impactos causados ao meio ambiente (DONAIRE, 1992).

Para tanto, é preciso assumir um compromisso com ações benéficas ao meio ambiente, procurando minimizar os impactos negativos e intensificar os positivos (DONAIRE, 1999).

Donaire (1992) trata da transformação organizacional enfocando a estrutura e o comportamento da empresa, partindo de críticas ao conceito de responsabilidade social para, em seguida, utilizar-se do conceito de conscientização social. A velocidade da implantação e consolidação da atividade de gestão ambiental, embora tenha influência da legislação específica e de pressões da comunidade, está fortemente condicionada à sua concepção na estrutura da empresa (DONAIRE, 1992).

Contudo, pode-se dizer que a interação entre o ser humano e a natureza é definida pelas relações de produção vigentes na sociedade. Portanto, a gestão socioambiental é um importante instrumento para capacitação e criação de competitividade para as organizações (ANDRADE \& TACHIZAWA, 2008).

E devido à relevância do assunto gestão socioambiental pelas organizações, que vem tomando discussões globais, que o presente trabalho retrata o estudo sobre a relação do Banco Real com as questões ambientais, identificando a abordagem da imagem corporativa a partir da visão do consumidor interno e externo, uma vez que, esse consumidor vem demonstrando interesse à preservação do meio ambiente.

\section{EMPRESAS E MEIO AMBIENTE}

Até meados do século XVIII, anteriormente à Revolução Industrial, a ação humana sobre a natureza ocasionava transformações, mas não tão profundas e irreversíveis como as que se seguiram após o início do processo de industrialização. 0 homem construía, caçava animais,

\footnotetext{
1 DREW, David. Processos interativos homem-meio ambiente. Tradução de João Alves dos Santos. 3.ed. Rio de Janeiro: Bertrand Brasil, 1994.
} 
recolhia frutos das árvores e derrubava matas para fazer plantações. Em geral, ainda havia um relativo equilíbrio nas relações do homem com a natureza.

Com o advento da Revolução Industrial e nos séculos seguintes, o desenvolvimento tecnológico, a explosão demográfica, a produção em larga escala, as demandas sempre crescentes, a competitividade desenfreada por mercados, a revolução das telecomunicações e da informática ocasionaram no mundo, novas formas de poluição do meio ambiente (SOUZA \& MILLER, 2003).

Segundo Dias (2007) é nesse sentido que podemos afirmar que o modelo resultante da Revolução Industrial é o responsável pela atual crise ecológica.

Para Dias (2007) a sociedade atual está baseada no crescimento contínuo do consumo e é essa sociedade que repousa sobre a exploração dos recursos naturais do planeta. Esse novo contexto apresentou como desafio para as empresas a busca por competitividade, produtividade e passou a preocupar com a sua reputação perante a sociedade em relação aos efeitos de impactos ambientais causados pela mesma.

Nesse sentido, a expansão da consciência coletiva com relação ao meio ambiente e a complexidade das atuais demandas ambientais que a sociedade repassa às organizações induzem um novo posicionamento por parte das organizações diante de tais questões (TACHIZAWA \& ANDRADE, 2008).

Cabe a consideração que um Sistema de Gestão Ambiental nas empresas pressupõe inicialmente a determinação de orientação política da organização e, posteriormente, a criação das condições objetivas para delineamento do sistema e sua estratégia de implantação.

Para Andrade, Tachizawa e Carvalho (2004) uma organização deve procurar adotar uma visão sistêmica, global e abrangente, que possibilite visualizar o início, o meio e o fim do processo, ou seja, as inter-relações entre recursos captados e valores por elas obtidos. 0 enfoque sistêmico abrange as operações, a gestão ambiental/ gerenciamento ecológico, gestão estratégica e o meio ambiente.

A participação tanto de indivíduos quanto de organizações é um aspecto fundamental para melhorar as condições do meio ambiente, "e para tanto são necessárias novas normas de conduta na relação do homem com a natureza, ou seja, uma ética ecológica” (DIAS, 2007).

\section{NORMAS AMBIENTAIS}

A Série ISO 14000, que envolve além da Gestão Ambiental, mais cinco normas relacionadas ao meio ambiente e aos produtos manufaturados. Segundo a ABNT a série ISSO 14000 consiste em um conjunto de normas ambientais voluntárias que contribui para a melhoria da qualidade do meio ambiente.

Segundo a NBR ISO 14001 (2004), a gestão ambiental é parte de um sistema global de administração que provê ordenamento e consistência para que as organizações abordem suas preocupações ambientais, através da alocação de recursos, voltados para planejamento, implementação, verificação e análise crítica pela alta administração para manter a política ambiental estabelecida pela empresa. 
A comissão européia lançou em 1995, o EMAS - Sistema Comunitário de Eco-Gestão e Auditoria ou Eco Management and Audit Scheme, que constitui um sistema de gestão ambiental (SGA) para todos os tipos de organizações, que permite avaliar, melhorar e dar conta do seu desempenho ambiental (KRAEMER, 2004).

Em 2001, reservada até então unicamente às empresas, as normas EMAS estenderam-se a outras organizações (ONG, serviços públicos etc.) e integrou as diretrizes da ISO 14001 como sistema de gestão ambiental de referência.

Em 2002, adotou a nova estratégia referente à Responsabilidade Social das Empresas (RSE), que visa realçar a contribuição das empresas para o desenvolvimento sustentável.

EMAS é instrumento importante da RSE, reconhecido como ferramenta-chave para orientar as exigências ambientais e para promover a inovação e a modernização dos processos.

Conseqüentemente, contribui para a competitividade das empresas.

\section{O SETOR BANCÁRIO E A QUESTÃO ECOLÓGICA}

A conscientização do setor bancário tomou maiores proporções a partir da década de 80, quando alguns bancos consideraram a conduta ambiental e social de seus clientes. Outro fator que proporcionou essa mudança de postura foi à legislação, a qual permite enquadrar os financiadores como responsáveis por projetos que afetam negativamente o meio ambiente (RIBEIRO \& LISBOA, 2000).

O crescimento da consciência ambiental modifica os padrões de consumo, constituindo assim uma das mais importantes armas em defesa do meio ambiente. As empresas identificam as oportunidades oferecidas pelos consumidores responsáveis, desenvolvem ações legítimas e verdadeiras, sendo que essas ações tendem a reforçar ainda mais a consciência ambiental (BARBIERI, 1997).

Desse modo, a crescente consciência ambiental da população motivou as instituições financeiras a incorporar as informações de natureza ambiental nas operações de concessão de crédito.

As questões ambientais tornam-se cada vez mais relevantes para as instituições financeiras, pois não é importante apenas sob o aspecto de gerenciamento de risco, também representa oportunidades de negócio e pode se tornar uma vantagem competitiva tanto para as empresas quanto para as instituições financeiras. Todos os parceiros dos bancos provocam impacto sobre o meio ambiente utilizando recursos naturais e geram resíduos ou emissão, e é nessa parceria que os bancos se relacionam indiretamente com as questões ambientais, além de também utilizarem recursos naturais e gerarem resíduos (TOSINI, 2005).

Como exemplo, pode-se citar o Banco Real na declaração em que afirma que: "As pessoas vem mudando seus hábitos de consumo. Cada vez mais valorizam seu poder de escolha, adquirindo produtos produzidos por empresas que respeitam o meio ambiente. Essa nova postura tem exigido das companhias um rápido processo de adaptação. Para estimular nossos 
clientes empresariais a realizar esse movimento, criamos financiamentos direcionados às áreas ambiental, educacional e social"2.

Algumas instituições financeiras vêem inserindo em suas políticas de crédito a análise de aspectos relativos ao meio ambiente, visando, principalmente, a defesa de seus interesses, agora sob a ótica do risco ambiental (RIBEIRO, 1998).

A análise socioambiental das práticas dos clientes é uma medida que faz com que todos ganhem. As instituições ganham porque mitiga os riscos do empréstimo, o meio ambiente e a sociedade ganham, pois vêem chances de serem menos impactados, e as próprias empresas analisadas ganham, pois seus negócios ganham solidez.

Para a elaboração de uma análise de crédito confiável de uma empresa é necessário que estas evidenciem as informações contábeis ambientais e assim as instituições financeiras poderão analisar os ativos, passivos, custos e despesas ambientais antes de conceder o crédito.

Ribeiro (1998) apresenta a seguinte definição para ativos ambientais: [...] são recursos econômicos controlados por uma entidade, como resultado de transações ou eventos passados, e dos quais se espera obter benefícios econômicos futuros, e que tenham por finalidade o controle, preservação e recuperação do meio ambiente.

Ainda o autor, a análise dos ativos ambientais das empresas, por parte de entidades financiadoras, visa verificar o empenho da empresa solicitante do crédito no processo de preservação do meio ambiente.

As instituições financeiras que adotam a análise de crédito ambientalmente corretas, buscam tais informações para verificar a real situação da empresa e assim, garantir a quitação dos empréstimos e/ou financiamentos concedidos e evitam ficar expostos também ao risco ambiental (TOSINI, 2005).

\section{IMAGEM, IDENTIDADE E COMUNICAÇÃO CORPORATIVA}

A imagem é como uma resultante de todas as experiências, impressões, posições e sentimentos que as pessoas apresentam em relação a uma mesma empresa, a um produto, a uma personalidade (BALDISSERA, 2003).

No que se refere à imagem corporativa Villafañe (2004) procura defini-la como: a síntese da identidade da organização manifestada a partir de seu comportamento, sua cultura e sua personalidade corporativas, os quais projetam uma imagem funcional, interna (auto-imagem) e intencional respectivamente e constroem na mente de seus públicos essa gestalt que é o que denomino de 'imagem corporativa.

A imagem é a diferença entre as percepções positivas e negativas que uma empresa causa em um determinado público. A imagem competitiva é aquela que gera negócios, conquista clientes, acionistas, parceiros, fornecedores, além de atrair os melhores profissionais para a empresa e conseguir a boa vontade de seus públicos, abrindo portas e doando credibilidade à organização (NEVES, 2000).

E a comunicação é um dos processos fundamentais dentro do contexto organizacional para expressar essa imagem corporativa.

2 Site oficial do BANCO REAL. Disponível em http://www.bancoreal.com.br/. Acesso em 04/05/09. 
A comunicação organizacional é como uma atividade administrativa com dois propósitos principais: fornecer informação e compreensão necessárias para que as pessoas possam se conduzir nas suas tarefas e proporcionar meios para a criação de atitudes necessárias à promoção da motivação, cooperação e satisfação nos cargos (CHIAVENATO, 1997).

A comunicação em uma organização é uma ferramenta que age na identidade organizacional, reforçando e preservando-a ou, impulsionando mudanças, uma vez que, engloba todo o fluxo de mensagens que compõem a rede de relações da organização (BALDISSERA, 2000). 0 objetivo da comunicação deverá ser informar sobre os atributos do produto, principalmente os aspectos positivos em relação ao meio ambiente, e transmitir a imagem da organização relacionada a essa variável (Dias, 2007).

Torquato (1986) sustenta que "identidade, mais que imagem, refere-se ao plano real. Imagem conota uma representação disto". Enfatiza que "quando a identidade não é fixada de maneira adequada, a sombra é muito tênue; identidade forte ajuda a passar uma imagem de fortaleza".

Essa tentativa de criação, por meio da imagem, atribui um aspecto de responsabilidade e preocupação com o meio ambiente.

Quando a empresa passa a valorizar sua relação com o meio ambiente e toma medidas preventivas, sua imagem perante a opinião pública tende a apresentar conotação diferenciada. Assim, a valorização para com o meio ambiente tem um forte papel na manutenção dos clientes atuais e atração de novos consumidores (RAGASSI E SCARPINELLI, 2003).

Contudo não há dúvida de que a administração da imagem por meio da comunicação é fator de vantagem competitiva.

Assim, torna-se imperativo o entendimento do processo de conhecimento sobre os conceitos de identidade organizacional e sua influência na construção do sentido de valor que a organização estabelece para com seus públicos e, da mesma forma, na consolidação de uma imagem corporativa ajustada aos interesses da mesma e compatível com as exigências do mercado (SANTOS, 2007).

\section{BANCO REAL ${ }^{3}$}

Fundados em 1917 e 1925, respectivamente, o Banco Holandês da América do Sul (buscava atender aos anseios dos comerciantes holandeses) e a Cooperativa Bancária (com o objetivo de oferecer crédito aos fazendeiros do estado), três anos depois renomeada como Banco da Lavoura de Minas Gerais, trilharam caminhos diferentes até a sua fusão no ocaso do século 20.

Em 1955, o Banco Mineiro se tornou a maior instituição financeira privada nacional, com 180 agências. E em 1957, já consolidada sua posição no Brasil, o Banco da Lavoura decide expandir suas operações para o exterior, abrindo um escritório em Nova York.

Já o Banco Holandês, ao contrário, concentrou-se nas operações de câmbio, créditos de curto prazo e contas correntes. Com o tempo, graças à associação com a Companhia Aymoré de Crédito, Investimentos e Financiamentos, em 1963, se tornou um banco múltiplo, em 1988, passando a diversificar suas atividades.

3 Caçadores do impossível. Disponível em:

http://www.fundacaofia.com.br/boletimfia/ed_18/pdf/abn_amro_real.pdf. Acesso em 13/07/09. 
Com a globalização, surgiu uma oportunidade para que o Banco Holandês consolidasse sua presença no mercado nacional. Então, em 1998 foi formalizada a aquisição do Banco Real pelo ABN Amro Bank, passando a se chamar Banco ABN Amro Real.

Em 2001, o Banco Real reduziu os impactos ambientais que produziam: cuidar do lixo e dos resíduos gerados em nossas operações. No ano seguinte, lançaram o programa de Ecoeficiência - produzir mais usando menos recursos naturais e compreender o conceito dos 3Rs (reduzir, reutilizar e reciclar).

Ainda no mesmo ano, o banco criou um grupo de trabalho para riscos socioambientais, tendo em vista a análise de práticas corretas para a concessão de crédito e financiamento. Além de aspectos econômicos, passaram a analisar questões sociais e ambientais envolvendo as operações de clientes corporativos. Entre os principais itens monitorados estão as licenças ambientais, disposição de resíduos sólidos, controle da poluição do ar e tratamento de efluentes líquido, além do número de acidentes, higiene, segurança e medicina do trabalho, indícios de trabalho infantil ou escravo e terceirização de processos poluentes e perigosos.

No período de 2004 a 2007, o banco conquistou 115 prêmios, contando todas as áreas de atuação e em 2008, o Grupo Santander passou a exercer efetivamente o controle societário indireto das empresas do conglomerado ABN AMRO Real no Brasil.

\section{ESTUDO DE CASO}

0 estudo de caso foi realizado em duas agências do Banco Real da cidade de Conselheiro Lafaiete/MG, a primeira agência (A) localizada no centro comercial, de maior porte e a outra agência (B) de porte menor, recém inaugurada em Dezembro de 2008, localizada em uma das principais avenidas de acesso da cidade e têm implantada o processo de Gestão Ambiental proposto pelo Banco Real, com o objetivo de analisar o comportamento do consumidor diante da imagem ambiental corporativa.

A agência A está no mercado a 79 anos e possui 20 funcionários e 25.000 clientes; a agência B está a 10 meses no mercado e possui 8 funcionários e 3.000 clientes.

Para o desenvolvimento do estudo de caso foi realizada uma pesquisa bibliográfica e pesquisa de campo exploratória, efetivada a partir da aplicação de entrevista estruturada através, do método questionário com perguntas semi-fechadas.

As entrevistas foram aplicadas no segundo semestre de 2009, nas instalações das duas agências da empresa pesquisada, de forma individual.

Quanto ao público, foi pesquisada uma amostragem de 190 clientes e 12 funcionários em uma agência do Banco Real (A) calculada com base em uma confiabilidade de 95\% e um erro estimado de 5\% e 7\%; e na outra agência do Banco Real (B) uma amostragem de 120 clientes e 8 funcionários calculada com base em uma confiabilidade de 95\% e um erro estimado de $7 \%$ e $9 \%$.

\section{APRESENTAÇÃO E ANÁLISE DOS RESULTADOS}

\section{Resultados das respostas ao questionário aplicado aos funcionários das agências A e B do Banco Real.}

Quando perguntados se tinham conhecimento das práticas ambientais, houve uma discrepância nas respostas. Na agência A, 100\% dos funcionários têm conhecimento das 
práticas ambientais e na agência $\mathrm{B}$, apenas $88 \%$ tem conhecimento destas práticas, embora seja uma agencia construída com base nos princípios de construção sustentável.

A grande maioria dos funcionários tem conhecimento da reciclagem (83\% na agência A e 75\% da agência B); coleta seletiva (33\% na A e 13\% na B) e financiamento socioambiental (16\% na A e $25 \%$ a B). Já a reutilização da água (38\%) e layout e placa solar (13\%) só são mencionados na agência $B$, pois apenas nela ocorrem tais procedimentos. Várias outras práticas ambientais realizadas pela instituição financeira não foram sequer citadas.

Daqueles que desconheciam as práticas ambientais da empresa (13\% na agencia B) todos responderam que o motivo era a "falta de tempo". Esta postura de falta de tempo (13\%) por parte de funcionários do banco é surpreendente, uma vez que, o Banco Real é uma das principais empresas que mais investe na sustentabilidade. Em contrapartida, todos os funcionários da agência A tem algum conhecimento das práticas ambientais.

Os funcionários entrevistados que disseram não conhecer as práticas ambientais, sendo eles $13 \%$ da agência $B$, não precisaram responder a questão 2 , então, nessas respectivas questões, $100 \%$ dos clientes da agência $A$ e $88 \%$ dos clientes da agência B responderam esta parte da questionário. E a partir da questão 3, 100\% dos funcionários das agências $\mathrm{A}$ e B responderam o questionário.

Daqueles que afirmaram conhecer as práticas ambientais da empresa $(100 \%$ da agencia A e $88 \%$ da agencia B) revelaram que se informam na própria agencia ( $83 \%$ na A e $63 \%$ na $B$ ). A mala direta (50\% na A e 38\% na B); Televisão (50\% na A e 38\% na B); Jornais (33\% A e 38\% na B) e Internet (16\% na A e 63 \% na B) são outros meios de informação mencionados.

A ampla maioria dos funcionários das duas agências (100\%), afirmaram que o fato do Banco Real adotar uma política ambiental influencia seu grau de satisfação com a organização.

\section{Resultados das respostas ao questionário aplicado aos clientes das agências A e B do Banco Real.}

Perguntados sobre o grau de satisfação com o Banco quando ele se vincula com práticas ambientais sustentáveis, revelaram satisfeitos e muito satisfeitos $(89 \%$ dos clientes da agencia A e $80 \%$ dos clientes da agencia B).Sendo que informaram serem indiferentes para eles (11\% da agencia A e $18 \%$ da B).

No entanto quando perguntados se tinham conhecimento das práticas ambientais executadas pelo Banco Real 54\% dos clientes da agencia A responderam que não; e a mesma resposta foi dada por $60 \%$ dos clientes da agencia B.

Daqueles que informaram ter conhecimento das práticas ambientais do Banco Real destacouse a reciclagem (36\% da A e $28 \%$ da B) e a coleta seletiva (5\% da A e $7 \%$ da B). Não se revelando significativo o conhecimento de outras práticas.

0 motivo alegado pelos respondentes foi; a falta de informação ( $20 \%$ da A e $22 \%$ da B); falta de interesse ( $9 \%$ da $A$ e $17 \%$ da B); falta de tempo (12\% da A e $3 \%$ da B), sendo que $9 \%$ dos clientes da A e 17 \% dos da B não informaram.

Os que tiveram acesso a informações obtiveram-nas na própria agência (12\% dos clientes da A e $10 \%$ da B); de mala direta (19\% da A e $12 \%$ da B); Televisão (21\% da A e 22\% da B), jornais (6\% da A e 7\% da B) e Internet (7\% da A e 5\% da B). 
Quando perguntados se a divulgação feita pelo banco era suficiente para o conhecimento dessas práticas ambientais, houve um relativo equilíbrio nas respostas entre o $\operatorname{sim}(39 \%$ do total das duas - A 16\% e B 23\%) e o "poderia melhorar" (35\% do total das duas - A 23\% e B $12 \%$ ) sendo que $9 \%$ dos clientes da agencia A e $3 \%$ dos clientes da agencia B não acham a divulgação suficiente para terem acesso às informações.

Questionados se mudariam de banco se este não adotasse práticas ambientais: afirmaram que $\operatorname{sim} 38 \%$ dos clientes da agencia $\mathrm{A}$ e $25 \%$ da B, sendo que o não foi respondido por $36 \%$ dos clientes da agencia A e $30 \%$ da agencia B. Revelaram que seria indiferente $26 \%$ dos clientes da agencia A e $45 \%$ daqueles da agencia $B$.

\section{CONSIDERAÇÕES FINAIS}

Conforme Donaire (1999), o fato de o meio ambiente ter sido considerado um recurso abundante e classificado na categoria de bens livres, daqueles bens para os quais não há necessidade de trabalho para sua obtenção, dificultou o estabelecimento de certo critério em sua utilização e tornou disseminada a poluição ambiental, que passou a afetar a totalidade da população, por meio de uma apropriação socialmente indevida do ar, da água ou solo.

A realização desta pesquisa de campo possibilitou um conhecimento sobre os funcionários e clientes de duas Agências do Banco Real em relação a suas percepções a respeito das questões ambientais realizadas pela instituição financeira.

De acordo com os resultados obtidos na pesquisa bibliográfica e de campo percebe-se que as organizações estão investindo na sustentabilidade devido a uma maior conscientização da população em relação à preservação ambiental.

A maior parte dos entrevistados está satisfeita em saber que a instituição financeira adota práticas ambientais (mesmo não tendo conhecimento de quais práticas se trata), mas muitos deles preocupam apenas com a instituição em satisfazer às suas necessidades, independente do seu vinculo favorável ao meio ambiente. Isso reforça que as instituições financeiras precisam divulgar mais informações expondo estas práticas ambientais e seus benefícios.

Devido à crescente conscientização em relação a questões que envolvem o ambiente natural, a comunicação interna e externa pode ser considerada essencial na transmissão destas informações focando nas práticas ambientais e na importância da participação da sociedade para continuidade e melhoria destas, e assim, constrói uma excelente imagem corporativa.

\section{REFERÊNCIAS BIBLIOGRÁFICAS}

ANDRADE, R.; TACHIZAWA, T.; CARVALHO, A. Gestão Ambiental: enfoque estratégico aplicado ao desenvolvimento sustentável. São Paulo: Makron Books, 2004.

ANDRADE, R.; TACHIZAWA, T. Gestão Socioambiental: estratégias na nova era da sustentabilidade. Rio de Janeiro: Elsevier, 2008.

BALDISSERA, R. Imagem-conceito: a indomável orgia dos significados. Trabalho apresentado no XXVI Intercom, Belo Horizonte/MG, setembro de 2003.

Comunicação organizacional: o treinamento de recursos humanos como rito de passagens. São Leopoldo: Unisinos, 2000. 
BANCO REAL. Disponível em http://www.bancoreal.com.br/. Acesso em 04/05/09.

BARBIERI, J.C. Competitividade Internacional e Normalização Ambiental. Anais IV Encontro Nacional sobre Gestão Empresarial e Meio Ambiente. São Paulo: nov. 1997.

CAPRA, F. Teia da Vida. São Paulo: Cultrix, 1996.

CHIAVENATO, Idalberto. Recursos Humanos. 4.ed. São Paulo: Atlas, 1997.

DIAS, Reinaldo. Marketing Ambiental: ética, responsabilidade social e competitividade nos negócios. São Paulo: Atlas,2007.

DONAIRE, D. Interiorização da Variável Ecológica na Organização das Empresas Industriais. São Paulo, Brasil, 1992. Tese de Doutorado - Faculdade de Economia Administração e Contabilidade, USP..

. Gestão Ambiental na Empresa. 2.ed. São Paulo: Atlas, 1999.

DREW, David. Processos interativos homem-meio ambiente. Tradução de João Alves dos Santos. 3.ed. Rio de Janeiro: Bertrand Brasil, 1994.

KRAEMER, M. E. P. Gestão ambiental na construção da imagem corporativa. XXIV Encontro Nacional de Engenharia de Produção - Florianópolis, SC, Brasil, 03 a 05 de Nov. de 2004.

LAYRARGUES, P. Sistemas de Gerenciamento Ambiental, Tecnologia Limpa e Consumidor Verde: a delicada relação empresa-meio ambiente no ecocapitalismo. Revista de Administração de Empresas, v.40, n.2, 2000.

NEVES, R. C. Comunicação empresarial integrada: como gerenciar imagem, questões públicas, comunicação simbólica, crises empresariais. Rio de Janeiro: Mauad, 2000.

RAGASSI, G. F.; SCARPINELLI, M. Marketing verde: ferramenta de gestão ambiental nas empresas. Revista Científica Eletrônica de Ciências Contábeis. Ano.I. n.02. Outubro,2003.

RIBEIRO, M. S. Custeio das atividades de natureza ambiental. São Paulo. Tese de Doutorado da Faculdade de Economia, Administração e Contabilidade (FEA) da Universidade de São Paulo, 1998.

RIBEIRO, M.S; LISBOA, L.P.. Passivo Ambiental. CONGRESSO BRASILEIRO DE CONTABILIDADE. Goiânia: FEA, 2000.

SANTOS JÚNIOR, H.A. Bancos e desenvolvimento sustentável. Rio de Janeiro: Boletim Legislativo Adcoas, n.12, 1994. Disponível em http://www.adami.adv.br/artigos.asp. Acesso em 06/05/09. Acesso em 02/05/2009.

SANTOS, L. C.. A importância dos estudos sobre Identidade para a Comunicação Organizacional. Publicado no XXX Congresso Brasileiro de Ciências da Comunicação Santos - 29 de agosto a 2 de setembro de 2007. Disponível em: www.intercom.org.br. Acesso em 02/05/2009.

SOUZA, C. S. e MILLER, D. S. O protocolo de Quioto e Mecanismo de desenvolvimento limpo: as reduções certificadas de emissões, sua natureza jurídica e a regulação do mercado de valores mobiliários, no contexto estatal pós-moderno. Comissão de Valores Mobiliários, 
2003.

TORQUATO, Francisco. Comunicação empresarial / comunicação institucional: conceitos, estratégias, sistemas, estruturas, planejamento e técnicas. São Paulo: Summus, 1986.

TOSINI, M. F.C. Risco ambiental para as instituições financeiras bancárias. Dissertação de Mestrado em Economia e Meio Ambiente - Instituto de Economia da Unicamp. Campinas, 2005.

VILLAFAÑE, Justo. La gestión profesional de la imagen corporativa. Madrid: Pirâmide, 2004. 